\title{
Design and Construction of a Shredding Machine for Recycling and Management of Organic Waste
}

\author{
Abhay Katiyar'1, Abhishek Gaur ${ }^{1}$, Aviral Shrivastava1, Mohd Ahmar Khan' ${ }^{1}$ \\ Navneet Pratap Singh1, Dr. Rahul Saini' ${ }^{2}$ Ms. Gaganpreet Kaur ${ }^{3}$ \\ ${ }^{1}$ Student, ${ }^{2}$ Assistant Professor, ${ }^{3}$ Associate Professor \\ 1,2,3Department of Mechanical Engineering, ABES Engineering College, Ghaziabad, Uttar Pradesh, India
}

\begin{abstract}
How to cite this paper: Abhay Katiyar | Abhishek Gaur | Aviral Shrivastava | Mohd Ahmar Khan | Navneet Pratap Singh | Dr. Rahul Saini | Ms. Gaganpreet Kaur "Design and Construction of a Shredding Machine for Recycling and Management of Organic Waste" Published in International Journal of Trend in Scientific Research and Development

(ijtsrd), ISSN: 24566470, Volume-3 | Issue-4, June 2019, pp.707-712, URL: https://www.ijtsrd.c om/papers/ijtsrd23 889.pdf
\end{abstract}

Copyright (C) 2019 by author(s) and International Journal of Trend in Scientific Research

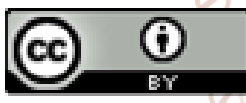
and Development Journal. This is an Open Access article distributed under the terms of the Creative Commons Attribution License (CC BY 4.0) (http://creativecommons.org/licenses/ by/4.0)

\section{ABSTRACT}

This research work accounts for the study of the significant problems of organic wastes management which is an issue utmost concern in developing Countries like India. Principally our aim is to minimize the jolt caused by organic Waste produced in agricultural fields as residue which is commonly burned causing pollution. We seek to reuse this valuable resource and turning into good quality compost for agricultural use. In this study, we designed and constructed a Shredding machine. The machine will initially convert larger particle size of Collected organic waste into desired size such that it can be treated other chemical and biological processes in order to convert it into compost in least amount of time possible. Indifferent from the conventional processes used this methodology elucidates the paramount problem of dumping, environmental pollution. In Addition to that it helps in farming by inducing the compost. As this methodology involves mechanical, chemical and biological processes for converting agricultural waste into compost making it highly efficient and ecofriendly which is need of the hour?

\section{INTRODUCTION}

In the present era of 21 st century the major problem in developing countries like India are the substantial problems arising due to organic waste which are being produced in such a substantial amount these days. Being agriculture dependent country India produces a large amount of organicresidues which then leads to the several problems of its disposal. These organic residues prevail upon the problems such as incineration, landfills, soil erosion, bad odour, air pollution and increase in carbon dioxide level in the atmosphere. Thus we need to ensure an efficient alternative to these problems. We plan to convert this organic waste into useful resource such as compost which adds on a considerable value to our farming.

\section{OBJECTIVES}

A. The existing system of conventional shredder machine is based on manual operating so it consumes more time for operation. Our main objective is to reduce time for operation.

B. To modify a machine this will produce less noise, vibrations and to reduce time consumption for shredding operation by modifying tool design.

C. To convert organic waste into valuable compost.

\section{LITERATURE REVIEW}

In 2010 Chevron $\mathbf{M}$ investigated the environmental impacts of centrifugal Spreader using organic compost and came to a conclusion that an Eco-innovative design should be Proposed to allow the designers to identify \& solve the environmental related problems.

In 2004 Per-Anders Hansson investigated the operations to remove the reed biomass from the lake \& to use it as nutrient supply in organic crop production \& came to a conclusion that if the positive effects of nutrient removal

from the lake are considered by all the three operations i.e. chopping, composting \& harvested biomass usage, then the total economics are highly improved.

In 2007 Dr.Salah M investigated the hidden economic value of agricultural waste, to study the converting of organic waste into fertilizers for farming by composting agricultural \& rural waste, to combine all the major sources of pollution/ wastes in one complex called Eco-rural park or environmentally balanced rural waste complex to produce fertilizer, energy, animal fodder \& other products \& came to a conclusion that it is necessary to make a sustainable nature of agricultural \& rural waste to reduce environmental pollution \& to avoid the depletion of the natural resources.

In 2012 M.A Repullo investigated the fertility of soil that is obtained by the use of Chopped or pruned Olive into different sizes \& came to a conclusion that the sample 
containing the largest amount of fine residues of Olive had the largest increase in SOM (Soil Organic Matter).

In 2016 Dr. K. Murlidharan investigated the By-Products obtained from various parts of coconut came to a conclusion that Coconut husk powder obtained after cutting the husk serves as a bed for the birds in the poultry

\section{METHODOLOGY}

Our process is based on the following steps:

$>$ Organic waste collection Shredding

$>$ Composting
$>$ Chemical and biological treatment

\section{Shedding:}

A shredder is a machine or equipment used for shredding (size reduction). Shredding systems are used to reduce the size of a given material. Industrial shredders are equipped with different kinds of cutting systems such as vertical shaft design, horizontal shaft design, single shaft, two shaft, three shaft and four shaft cutting systems, Bio-degradable waste decomposes faster when shredded.

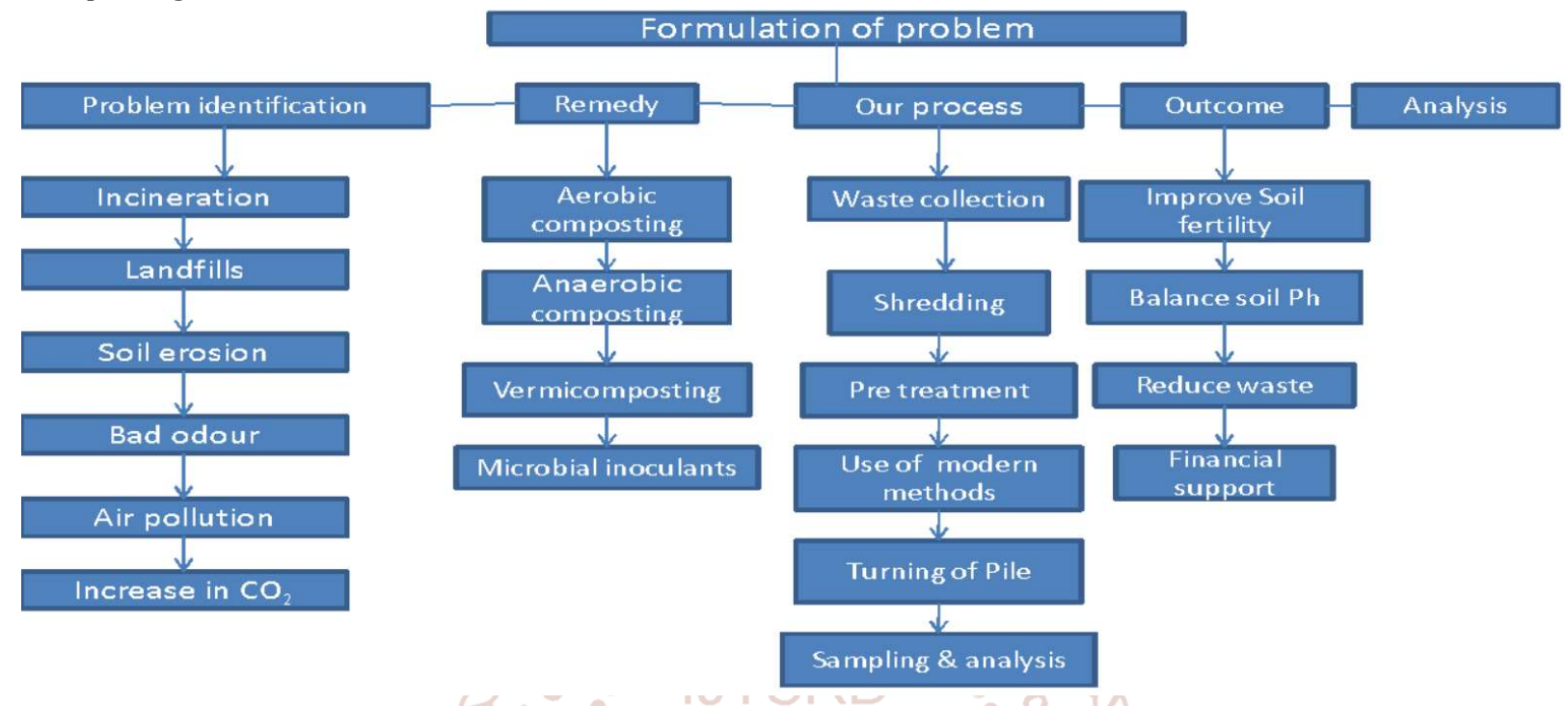

As per our requirement the size of shredded Particles should be between $8-12 \mathrm{~mm}$ which has been analysed by reviewing research paper Mentioned https://www.sciencedirect.com/science/article/ pii/S0959652616310228

\section{Composting:}

The process of controlled biological maturity under aerobic conditions, where organic matter of animal or vegetal origin is decomposed to materials with shorter molecular chains, more stable, hygienic, humus rich, and finally beneficial for the agricultural crops and for recycling of soil organic matter. The process is mediated by different microorganisms actuating in aerobic environment: bacteria, fungi, actinomycetes, algae, and protozoa, which participate naturally in the organic biomass or are added artificially. The process can be described by the follow equation:

\section{Organic matter $+02 \rightarrow$ compost $+\mathrm{CO} 2+\mathrm{H} 20+\mathrm{NO} 3-+$ S042- + HEAT}


$>$ The thermophilic phase (high temperature phase), with duration from some days until several months.

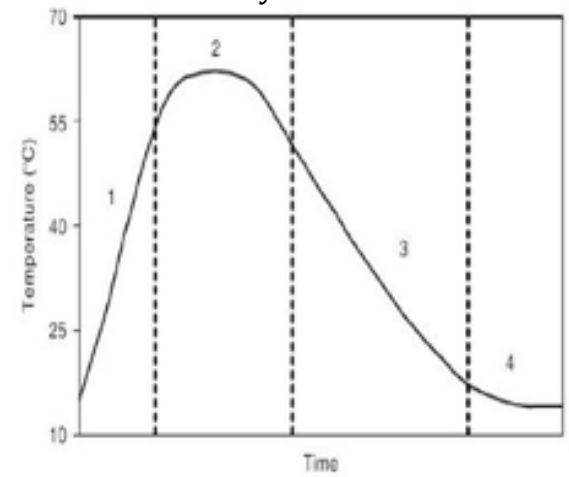

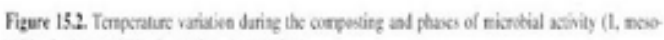

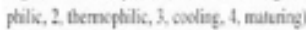

At temperature above 55C, many human and plant pathogens are destroyed, while seeds of weeds and parasites are destroyed when it reaches 60C. Temperature must not exceed 65C, because many useful microbes will be killed, resulting in a decrease of the rate of decomposition. For that purpose, the compost managers should use aeration and mixing to maintain the temperature below this point

\section{C/N RATIO}

Carbon provides an energy source and the building material representing $50 \%$ of the microbial cell biomass.

$>$ Nitrogen is a critical component of the proteins, nucleic acids, enzymes, and coenzymes necessary for cell growth and function.

$>$ The ideal $\mathrm{C} / \mathrm{N}$ ratio for composting is /generally considered to be around 30:1.

$>$ HUMIDITY

$>$ It is necessary for the nutrients exchange via cell membranes.

$>$ It is a transport environment for the extracellular enzymes and soluble substrates.

$>$ Optimal humidity of the compost is $50-60 \%$.

$>$ When it increases higher than 65\%, anaerobic conditions can be established,.

$>$ while values below $40 \%$ reduce the biological activity of the compost OXYGEN AND PH

$>$ The oxygen is also an essential ingredient for successful composting, aerobic process.

$>$ Although the atmosphere contains 21\% oxygen, the aerobic microbes can survive at concentrations as low as $5 \%$.

$>$ In this sense a content of $10 \%$ of oxygen is considered optimal for the composting.

$>$ On the other hand, a pH between 5.5 and 8.5 is optimal for compost micro-organisms.

$>$ When the bacteria and fungi digest organic matter, they release organic acids.

$>$ As the $\mathrm{pH}$ decreases, the growth of fungi increases, followed by decomposition of lignin and cellulose. If the system becomes anaerobic, the acid accumulation can lower the $\mathrm{pH}$ to 4.5 , thus limiting the microbial activity.

\section{PARTICLE SIZE}

Total free space is defined here as the relation between the volume of free space and the volume of biomass, expressed in percentage. On the other hand, free air space (FAS) is the volume occupied by the air as a part of the total free space.
Va is volume of water,

And Vt is total volume of biomass.

FAS is a very important parameter, because it influences the compost capacity to retainoxygen. In normal conditions, the value of total free space is between $35 \%$ and $50 \%$.

\section{IMPROVEMENTS INVOLVED}

As per the given study the modifications were made in composting process which is extremely beneficial https://link.springer.com/article/10.1007/s4009 3-016-
0147-1

Chemical treatment of ground fresh waste with $\mathrm{HCl}(0.25 \mathrm{~N}$, $50 \mathrm{ml} \mathrm{kg-1})$ for $30 \mathrm{~min}$ followed by $\mathrm{KOH}(0.5 \mathrm{~N}, 100 \mathrm{ml} \mathrm{kg}-1)$ for $30 \mathrm{~min}$ at $100^{\circ} \mathrm{C}$, and ambient pressure yielded a product that could be used in place of conventional organic manure. Only 8-14 h were required to complete the entire process. No by-product or leachate was produced. The quality of the product was comparable to that of conventional composts, except for the absence of microorganisms. The fortified organic fertilizer enhanced the yield of vegetables in pot trials. The process and the prototype machine were found beneficial by a public evaluation. Economically feasible

\section{Table 15.3. Humidity of different organic matters}

\begin{tabular}{lc}
\hline Organic matter & Humidity $(\%)$ \\
\hline Organic fraction of municipal solid wastes & $70-80$ \\
Sludge & $70-80$ \\
Beef manure & $75-80$ \\
Birds farm litter & $40-60$ \\
Juniper's wood & $70-75$ \\
Wheat straw & $15-20$ \\
Maize's steams & $25-35$ \\
\hline
\end{tabular}

\section{SYSTEM DESIGN}

Software used for designing is SOLID WORKS. Organic waste shredder machine from design point of view consists of following parts:

Total free space $=V v=V t$; FAS $1 / 4(V v-V a)=V t$ Where, $\mathrm{Vv}$ is volume of free space, 


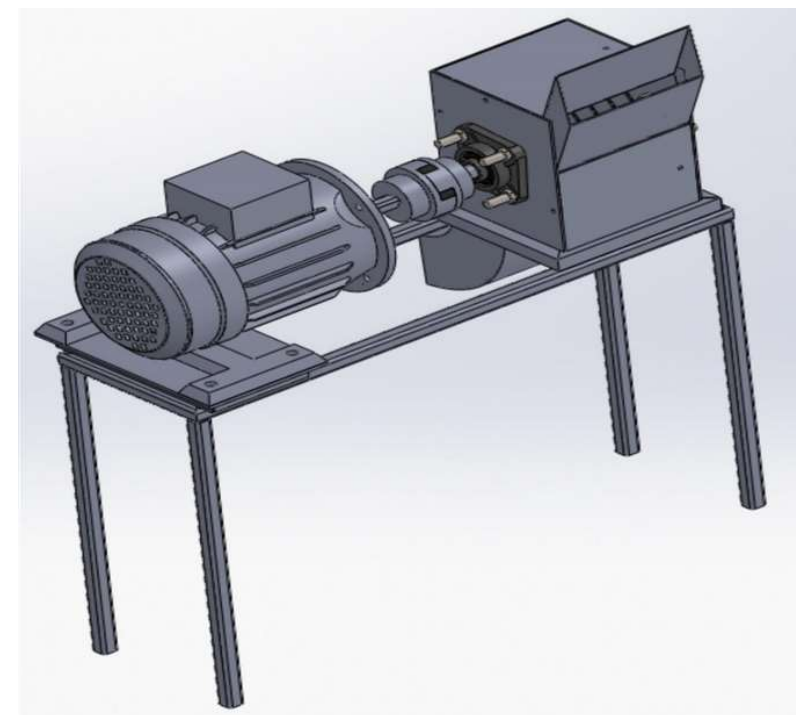

Shaft

A shaft is rotating machine element, usually circular in cross section and which is used to transmit power from one part to another part or from a machine which is power producer to power machine, which absorbs power. The various members such as cutting blades, gears and pulley are mounted on it. Circular shaft is used with one keyway (square) has a circular cross section for cutting system. Material is used for shaft is EN31 steel.

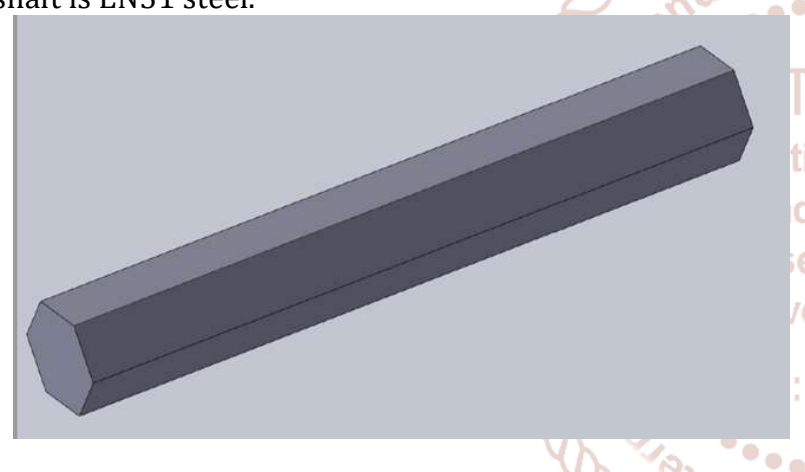

Power $=1 \mathrm{hp}=746 \mathrm{~W}$

Where,

$\mathrm{T}=$ Torque transmitted by the shaft $(\mathrm{N}-\mathrm{r}$

$\mathrm{p}=$ Transmitting power (kw).

$\mathrm{n}=$ Speed of transmission shaft(rpm).

$$
\begin{aligned}
& \mathrm{T}=\mathrm{P} / \boldsymbol{\omega} \\
& \mathrm{T}=\mathrm{P} \times 60 \\
& 2 \pi \mathrm{N} \\
& =\underline{746 \times 1000 \times 60} \\
& 2 \pi \times 600 \\
& \mathrm{~T}=11.872 \mathrm{~N}-\mathrm{m} \\
& \mathrm{T}=11827 \mathrm{~N}-\mathrm{mm} \\
& d=\sqrt[3]{\frac{\left(16 x_{1} \sqrt{\left[\left(B_{b} \times M_{b}\right)^{2}+\left(R_{t} \times M_{t}\right)^{2}\right]}\right.}{\pi x_{\text {max }}}}
\end{aligned}
$$

From Design data hand book

K. Mahadevan Eq... (9.10)

Max bending moment $=\mathrm{M}_{\mathrm{b}}$

Max torque $=M_{t}$

$\tau_{\max }=$ Max shear stress $\left(\mathrm{N} / \mathrm{mm}^{2}\right)$

$$
\tau_{\max }=\frac{\sigma_{y} \times 0.5}{f s}
$$

$\sigma_{y}=$ yield stress
$\tau_{\max }=\frac{310 \times 0.5}{3}$

$$
\tau_{\max }=33.33 \mathrm{~N} / \mathrm{mm}^{2}
$$

\section{BENDING MOMENT}

From analysis of bending moment diagram,

Maximum Bending moment, $\mathrm{Mb}=605.81 \mathrm{~N} / \mathrm{mm}^{2}$

\section{Cutting Force}

$$
\mathrm{FC}=190 / \text { Cutter } \times 9.81
$$

cutter $=20$

$$
\begin{aligned}
& \mathrm{FC}=19 \mathrm{Q} \\
& 20 \times 9.81 \\
& \mathrm{FC}=0.9693 \mathrm{~N}
\end{aligned}
$$

Also,

$$
\begin{aligned}
& \mathrm{T}=60 \times \mathrm{p} \\
& 2 \pi n \\
& \mathrm{~T}=60 \times 746 \\
& 2 \times 3.14 \times 550 \\
& \mathrm{~T}=12.95 \mathrm{~N}-\mathrm{m}
\end{aligned}
$$

Diameter of shaft :

$$
\begin{aligned}
& d=\sqrt[3]{\frac{\left(16 \times \sqrt{\left[\left(K_{b} \times M_{b}\right)^{2}+\left(K_{t} \times M_{t}\right)^{2}\right]}\right.}{\pi \times \tau_{\max }}}
\end{aligned}
$$

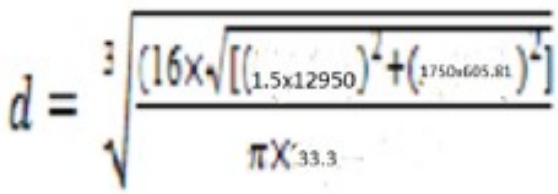

The diameter of the shaft is given by the equation: $\mathrm{d}^{3}=16 / \pi(\mathrm{Ss} \sqrt{\mathrm{M} b \times \mathrm{K} b})^{2} \times(\mathrm{M} t \times \mathrm{K} t)^{2}$

Where,

$\mathrm{M} t=$ maximum torsion moment, $324 \mathrm{Nm}$ (calculated)

$\mathrm{K} b=$ combine shock and fatigue applied to bending, 1.5

$\mathrm{Kt}=$ combine shock and fatigue applied to torsion, 1.0

Ss = allowable shear stress for shaft with keyways, Using a factor of safety of 0.9 Thus, a shaft of $30 \mathrm{~mm}$ is selected.

\section{HOPPER}

\section{Slant Height}

L1 $=$ Top length of hopper $=240 \mathrm{~mm}$ 
B1 $=$ Top breadth of hopper $=240 \mathrm{~mm}$

L2 $=$ Bottom Length of hopper $=120 \mathrm{~mm}$

B2 $=$ Bottom breadth of hopper $=120 \mathrm{~mm} \mathrm{H}=$ Height

$\mathrm{S}=$ Slant height

$\emptyset=$ Angle of inclination of hopper

2.3.13 Volume of Hopper

The volume of hopper is calculated using: Volume of hopper, $\mathrm{Vh}=\mathrm{Vb}-\mathrm{Vsm}$ Where $\mathrm{Vb}=$ volume of inlet

$\mathrm{Vsm}=$ volume of outlet

\section{CUTTING BLADES}

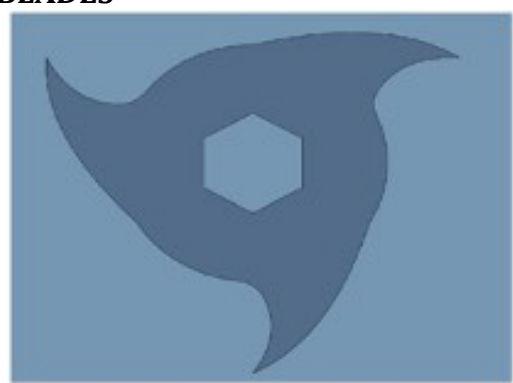

Cutting system consists of the shafts, cutting blades, washers and gears. The cutting blade is round-shaped blade with 3 (three) cutting edges, given circle-shaped hole in the middle with keyway, mounted on the main shaft and main shaft move together]. In drawing of cutting blades in Creo 3.0 software, cutting blades are equally divided into certain degree of angle and each cutting edge of cutting blade is joined by arc to second cutting edge up to particular length of cutting edge. We design the cutting system in such a way that angle between keyway of each cutter blade is 40 degree. And cutting blades are placed in such a manner that after first blade apart 40 degree from second blade. This concept used in shredder machine. Because of that, power which was requiring to rotate the shaft was large. Now that power to rotate the shaft is lesser than previous. Material used for cutting blade is mild steel.

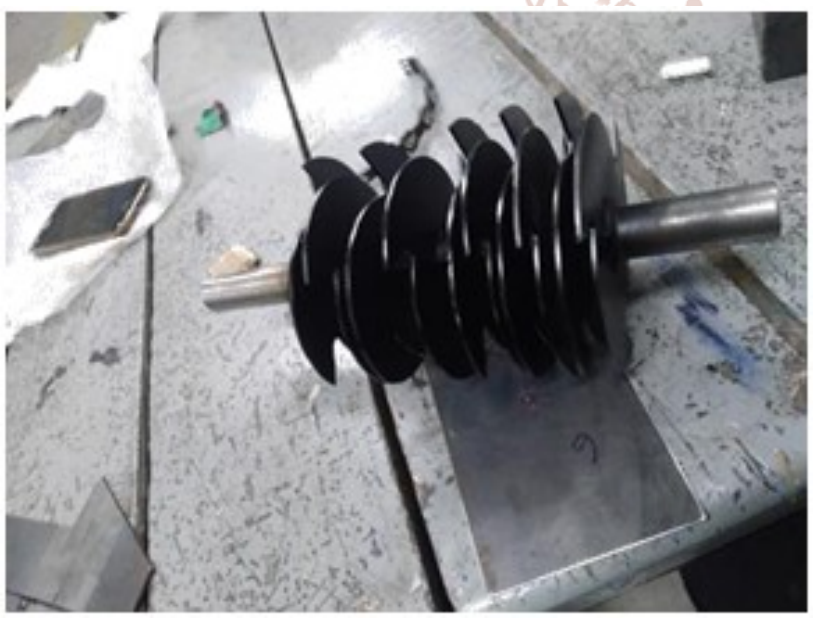

Analysis result:

Total deformation of cutting blade Cutting forces

$\mathrm{F}_{\mathrm{c}}=(\mathrm{Ks} * \mathrm{~S}) / \mathrm{G}$

$\mathrm{F}_{\mathrm{c}}=$ cutting forces $(\mathrm{kg})$

$\mathrm{K}_{\mathrm{s}}=$ tear strength $(\mathrm{n})$

$\mathrm{S}=$ max paper load

$\mathrm{G}=$ gravity $\left(\mathrm{m} / \mathrm{s}^{2}\right)$

$\mathrm{F}_{\mathrm{c}}=\mathrm{F}_{\mathrm{c}}{ }^{*}$ no. of blade

$\mathrm{T}=\mathrm{F}_{\mathrm{c}}{ }^{*} \mathrm{D} / 2$

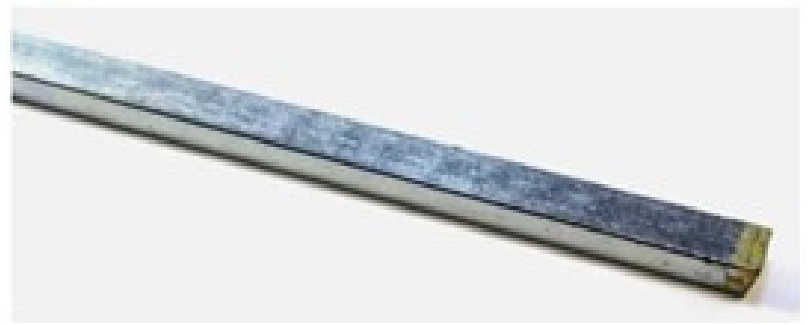

A key is machine element used to connect a rotating machine element to shaft they key present relative rotation between the two parts and many enable torque transmission. Square key use in machine shaft. Material used for key is steel. Dimensions are obtained by designing of key: width of key, height of key, length of key. The shaft key is maximum allowable shear stress.

Width of key, $\mathrm{w}=\mathrm{d} / 4$

Thickness of key, $t=$ Where,

$\mathrm{d}=$ inner diameter of the shaft to be selected,

\section{MOTOR}

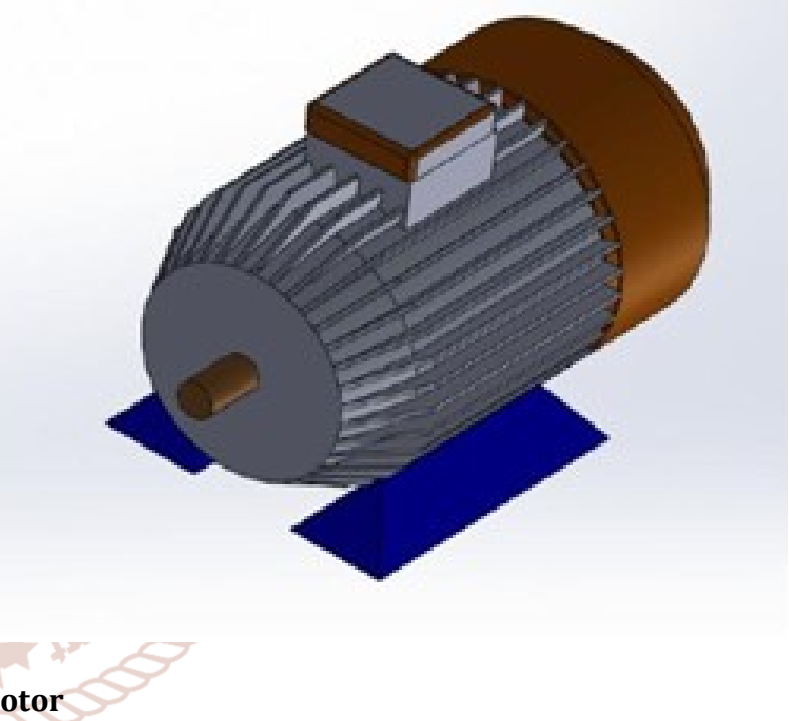

Electric motor is electrical device that converts electrical energy into mechanical energy. In certain applications, such as in the transportation industry with traction motors, electric motors can operate in both motoring and generating or braking modes to also produce electrical energy from mechanical energy.

\section{Motor Specification:}

1. Type-3 Phase Induction motor

2. Input power - $550 \mathrm{watt} / 1 \mathrm{HP}$

3. Input speed - $1405 \mathrm{rpm}$

4. Input torque $-3.738 \mathrm{Nm}$

\section{Jaw type coupling}

\section{KEY}




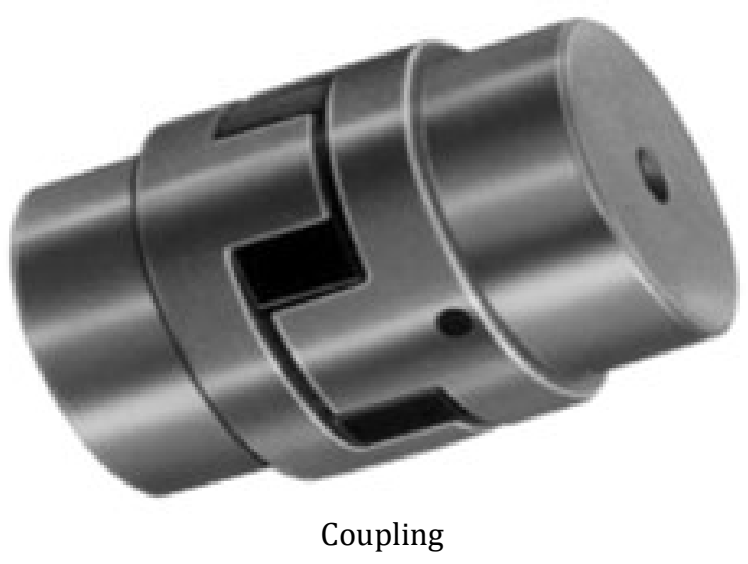

A coupling is a type of general purpose power transmission coupling that also can be used in motion control (servo) applications. It is designed to transmit torque (by connecting two shafts) while damping system vibrations and accommodating misalignment, which protects other components from damage. Jaw couplings are composed of three parts which are consisting of two metallic hubs and an elastomer insert called an element, but commonly referred to as a "spider". Considerations for elastomer selection include ability to dampen vibration, ability to handle misalignment, operational temperature range, speed of equipment, and chemical conditions. Jaw couplings are considered "fail-safe" because, should the elastomer fail or wear away, the jaw coupling hub teeth will mate, much like teeth on two gears, and continue to transmit torque.

\section{BEARING}
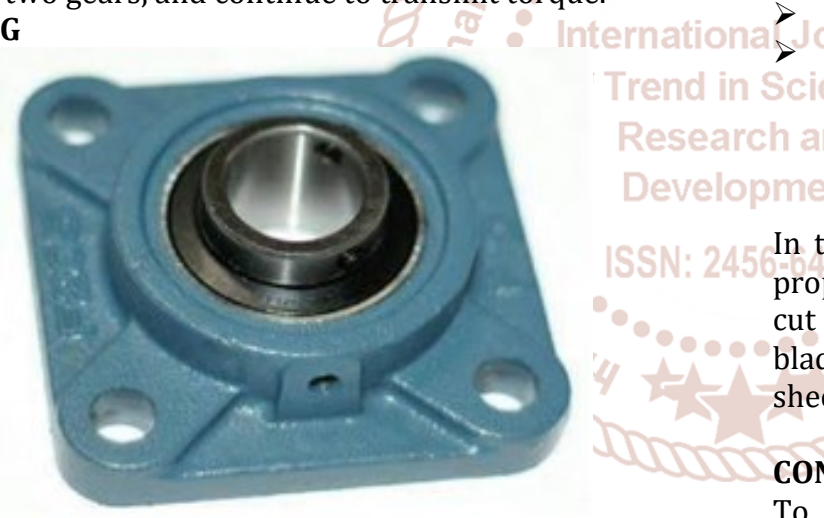

Supporting stand is made up of mild steel with $1000 \mathrm{~mm}$ length and $500 \mathrm{~mm}$ breadth respectively.

\section{RESULT}

As we made the design according to requirements, the necessary calculations were also carried out. We designed the other shredding elements such as spur gear, shaft, cutting blade, jaw type coupling, bearing, key and frame etc. Main elements which are gear box and motor this are most important to shred more efficiently than previous. Also, because of design and automation time for operation is reducing to greater extent than previous one. Therefore this machine was less time consuming as compared to manual shredder.

Increased organic matter in soils, improved drainage in clay soils, and controlled soil erosion.

$>$ Improved soil properties and associated plant growth; it builds sound root structure, reduces plant stress from drought and frosts, improves nutritional content of food grown in compost-rich soils.

$>$ Reduced environmental impacts due to reduced soil erosion, water logging, nutrient loss, surface crusting, eutrophication of waterways, siltation of waterways, etc. Boosts soil microbial population.

Improved water retention in sandy soils and reduces water demands of plants. - Balances soil $\mathrm{pH}$ (acidity=alkalinity).

Reduces waste.

Pollution control. • Reduce emission of CO2

Financial support.

Potential use of available resources Noise and vibrations also reduced by proper designing and rubber material used for insulation of vibration (appropriate damping capacity).

In the last stage i.e. checking whether the machine runs properly or not, it was observed that the waste was getting cut into desired size but it was returning again with the blades. This did not allow us to put the other sheet. If other sheet was put, the machine used to stop automatically.

\section{CONCLUSION}

To minimize the limitation of conventional shredder machine, the atomize paper shredder machine is more applicable and economically feasible. We are developing a prototype model to fulfill the requirement. So, this project will more applicable in short scale industries and can be used by farmers. After discussing with industrial person and after discussion of literature review, it was found that the conventional machine has more limitation. To minimize the limitation of conventional machine, some modification is suggested in review paper, on the basis of the information, we are developing a prototype model of shredder machine. Such paper shredder machine is useful for conversion of organic waste into compost.

\section{ACKNOWLEDGEMENT}

It gives us immense pleasure to present our research paper titled "DESIGN AND CONSTRUCTION OF A SHREDDING MACHINE FOR RECYCLING AND MANAGEMENT OF ORGANIC WASTE". We are thankful to our honourable HOD ME Dr. Rajendra Kumar Shukla MS. Gaganpreet Kaur Dr. Rahul Saini and Department of Mechanical Engineering from ABES engineering college, Ghaziabad for their valuable support and encouragement. 


\section{REFERENCES}

[1] Joseph Y. Ko.,"Paper Shredding Device”,U.S.Patent 6390397B1, 2002.

[2] Ming-Hui Ho,"Blade of Paper Shredder”,Taipei (TW) Patent 6513740B2,2003.

[3] Gu-Ming Zeng,"Blade of Paper Shredder”,U.S. Patent 0040934A1, 2006

[4] Frank Chang,"Blade Assembly for Paper Shredder",U.S. Patent 6089482,2000.

[5] Kent Chen,"Cutter Structure of Shredder Blade”,Shanghai (CN) Patent 7641136B2,2010,

[6] ,"Rotation Speed Controlling System for Shredder Motor", Taipei (TW) Patent 8008882B2,2011.

[7] Tie Chun Wang,"Device For Reducing Vibrations And Noises Of Paper Shredder",San Chung (TW) Patent 7445173B2,2008.

[8] Mark S. Allen,"Lubricant Carrying Substrate for Maintenance for Paper Shredder",UT (US) Patent $716656 \mathrm{~B} 2,2007$.

[9] M.Sanjay Kumar, DR. T.R. Hemant Kumar, “Design and Development of Agricultural Waste Shredder Machine", IJISET, Vol. 2 Issue 10,2015

[10] Prof. S.Nithyanath, libin Samuel, Design and shredder machine, ISSN 487-491, 2014. 